\title{
A MODIFIED POWER FLOW METHOD FOR NON SYNCHRONOUS NETWORKS INTERCONNECTION
}

\author{
K.M. Shebl * \\ M. E. El-Said * \\ H. El-Desouki ** \\ I. Bedir *** \\ * Electrical Power \& Machines Dept., Faculty of Eng . Mansoura University \\ ** AAST, Alexanderia, Egypt \\ *** Electrical Power \& Machines Dept., Faculty of Eng . Tanta University
}

\begin{abstract}
This paper presents an efficient method for AC-DC power flow used in non- synchronous interconnection. The proposed method treats the converter as voltage dependent loads and the variables are eliminated from the power flow equations. The method is successfully implemented to IEEE 5-bus test system interconnected with IEEE 14-bus test system. The technical conditions for interconnecting power systems, the short circuit capacity of $\mathrm{AC}$ connected bus, the geometrical topology of the land in DC link path, and location of $\mathrm{AC}$ bus from the generating stations, are considered.
\end{abstract}

\section{INTRODUCTION}

HVDC transmission is now an acceptable alternative way to $\mathrm{AC}$ transmission, and is proving an economical solution not only for very long distance but also for underground cable and submarine transmission. It also a suitable mean of interconnecting systems of different frequencies or with problems of stability or fault capacity.

power flow analysis is an essential component of system studies carried out for planning, design and operation of power systems. It is basically a simulation of steady-state load and determines the operating point, which is later used for initializing variables in transient and dynamic system analysis. The basic load flow has to be substantially modified to be capable of modeling the operating state of the combined AC and DC system under the specified load conditions, generation and DC system control strategies.

Traditionally, two different approaches have been used to solve the power flow equations for AC-DC systems. The first approach is the unified method

Manuscript received from $D r . K . M$. Shebl

on : $20 / 5 / 2000$

Accepted on : 6/6/2000

Engineering Research Bulletin, Vol 23,No 3, 2000 Minufiya University, Faculty of

Engineering, Shebien El-Kom, Egypt, ISSN 1110-1180 
$[1,2,3, \& 4]$, which gives full recognition to the interdependence between $\mathrm{AC}$ and DC system equations and simultaneously solve the complete set of equations. The solution vector is extended with the DC-variables. Also, the Jacobian matrix will be modified to include the $D C$ system effect. The drawback of the unified method is that it is complex to program and difficult to combine with developments in $\mathrm{AC}$ power flow solution techniques, such as the fast decoupled method. The other approach is the sequential method $[2,4]$, in which the $\mathrm{AC}$ and $\mathrm{DC}$ equations are solved separately and thus the integration into existing load-flow programs is carried out without significant modification or restructuring of the $\mathrm{AC}$ solution technique. For the $\mathrm{AC}$ iterations, each converter is modified simply by the equivalent real or reactive power injection at the terminal busbar. The terminal busbar voltages obtained from the $\mathrm{AC}$ iteration are then used to solve the $\mathrm{DC}$ equations and consequently, new power injections are obtained. This process continues iteratively to convergence. The sequential method is easy to implement, but convergence problems may occur at certain modes of operations. The new method used for AC-DC power flow, which is explained in [5] is used here to overcome the above difficulties, and can be used for interconnecting of electrical power system.

\section{SYSTEM MODELS}

\subsection{SYSTEM MODELS}

The objective of HVDC system model is to develop a generic bipolar or monopolar HVDC model [4,5, \&6], which represents multi-terminal and multi-converter DC systems integrated with the AC system. The model must also be able to the more complex control Actions that are invariably associated with system configurations. The model of monopolar configuration is illustrated in Equs (1-9):

$$
\begin{aligned}
& \mathrm{V}_{\mathrm{dR}}=\frac{3 \sqrt{2}}{\pi} \cdot \mathrm{a}_{\mathrm{R}} \cdot \mathrm{V}_{\mathrm{IR}} \cdot \cos \alpha_{\mathrm{R}}-\frac{3}{\pi} \cdot \mathrm{x}_{\mathrm{C}} \cdot \mathrm{I}_{\mathrm{d}} \\
& \mathrm{P}_{\mathrm{dR}}=\mathrm{V}_{\mathrm{dR}} \cdot \mathrm{I}_{\mathrm{d}} \\
& \mathrm{S}_{\mathrm{dR}}=\frac{3 \sqrt{2}}{\pi} \cdot \mathrm{k} \cdot \mathrm{a}_{\mathrm{R}} \cdot \mathrm{V}_{\mathrm{tR}} \cdot \mathrm{I}_{\mathrm{d}} \\
& \mathrm{Q}_{\mathrm{dR}}=\sqrt{\mathrm{S}^{2} \mathrm{dR}-\mathrm{P}_{\mathrm{dR}}^{2}} \\
& \mathrm{~V}_{\mathrm{dR}}=\mathrm{V}_{\mathrm{d} \mathrm{l}}+\mathrm{I}_{\mathrm{d}} \cdot \mathrm{R}_{\mathrm{d}}
\end{aligned}
$$


$\mathrm{V}_{\mathrm{dI}}=\frac{3 \sqrt{2}}{\pi} \cdot \mathrm{a}_{\mathrm{I}} \cdot \mathrm{V}_{\mathrm{tI}} \cdot \cos \gamma_{\mathrm{I}}-\frac{3}{\pi} \cdot \mathrm{X}_{\mathrm{C}} \cdot \mathrm{I}_{\mathrm{d}}$

$P_{\mathrm{dI}}=\mathrm{V}_{\mathrm{dI}} \cdot \mathrm{I}_{\mathrm{d}}$

$\mathrm{S}_{\mathrm{dI}}=\frac{3 \sqrt{2}}{\pi} \cdot \mathrm{k} \cdot \mathrm{a}_{\mathrm{I}} \cdot \mathrm{V}_{\mathrm{tI}} \cdot \mathrm{I}_{\mathrm{d}}$

$\mathrm{Q}_{\mathrm{dl}}=\sqrt{\mathrm{S}_{\mathrm{dl}}^{2}-\mathrm{P}_{\mathrm{dl}}^{2}}$

where

$V_{d R}, V_{d I} \quad$ Voltage of $D C$ side of converter and inverter.

$\mathrm{V}_{\mathrm{t}}, \mathrm{V}_{\mathrm{tI}} \quad$ Voltage of converter and inverter AC bus.

$a_{R}, a_{l} \quad$ Converter and inverter transformer tap ratio.

$I_{d} \quad$ DC current.

$\alpha_{R} \quad$ Converter firing angle.

$\alpha_{1} \quad$ Inverter firing angle.

$\mathrm{X}_{\mathrm{C}} \quad$ Commutation reactance.

$\mathrm{R}_{d} \quad$ DC line resistance.

$\mathrm{K}$ is a constant very close to unity, and equal to 0.995 for power flow analysis $[2,4,85]$.

\subsection{AC-DC Power Flow Equations}

The basic load flow has to be substantially modified to be capable of modelling the operating state of the $A C$ and $D C$ systems under specified conditions of load, generation and DC system control strategies.

The power mismatches for all $\mathrm{AC}$ buses can be calculated using the Equ (4):

$$
\begin{aligned}
& \Delta P(V, \theta)=P^{\text {spec }}-P(V, \theta) \\
& \Delta Q(V, \theta)=Q^{\text {spec }}-Q(V, \theta)
\end{aligned}
$$

When the DC link is included in the power flow equations, only the mismatch equations at the converter and inverter terminal buses have to be modified as $[4,5]$,

$$
\begin{aligned}
& \Delta P_{\mathrm{tR}}=P_{\mathrm{tR}}^{\text {spec }}-P_{\mathrm{tR}}^{\mathrm{spec}}(V, \theta)-P_{\mathrm{dR}}\left(V_{\mathrm{tR}}, V_{\mathrm{tl}}, X_{\mathrm{dc}}\right) \\
& \Delta P_{\mathrm{tl}}=P_{\mathrm{tl}}^{\mathrm{spec}}-P_{\mathrm{tl}}^{\mathrm{spec}}(V, \theta)+P_{\mathrm{dl}}\left(V_{\mathrm{tR}}, V_{\mathrm{tl}}, X_{\mathrm{dc}}\right) \\
& \Delta Q_{\mathrm{tR}}=Q_{\mathrm{tR}}^{\mathrm{spec}}-Q_{\mathrm{tR}}^{\mathrm{spec}}(V, \theta)+Q_{\mathrm{dR}}\left(V_{\mathrm{tR}}, V_{\mathrm{tl}}, X_{\mathrm{dc}}\right)
\end{aligned}
$$




$$
\Delta \mathrm{Q}_{\mathrm{d}}=\mathrm{Q}_{\mathrm{di}}^{\mathrm{sec}}-\mathrm{Q}_{\mathrm{d}}^{\mathrm{pec}}(\mathrm{V}, \theta)+\mathrm{Q}_{\mathrm{dl}}\left(\mathrm{V}_{\mathrm{R}}, \mathrm{V}_{\mathrm{t}}, \mathrm{X}_{\mathrm{dc}}\right)
$$

where $\mathrm{X}_{\mathrm{dc}}$ is a vector of internal $\mathrm{DC}$-variables.

The DC- variables must satisfy

$\mathrm{R}\left(\mathrm{V}_{\mathrm{tR}}, \mathrm{V}_{\mathrm{tl}}, \mathrm{X}_{\mathrm{dc}}\right)=0$.

The of internal DC- variables are given as,

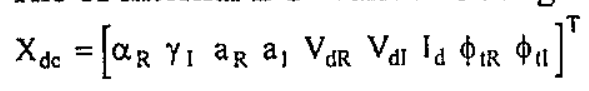

where

$\mathrm{p}(\mathrm{v}, \theta), \mathrm{Q}(\mathrm{v}, \theta)$ the injected active and reactive power at $\mathrm{AC}$ buses.

$\mathrm{V}, \theta$

$\mathrm{P}^{\text {spec }}, \mathrm{Q}^{\text {spec }}$ vector of $\mathrm{AC}$ bus voltage magnitude and phase angle.

$\Delta \mathrm{P}, \Delta \mathrm{Q}$ specified active and reactive power at $\mathrm{AC}$ buses.

$P_{t}^{\text {spec }}, Q_{t}^{\text {spec }}$ vector of active and reactive power mismatch

$P_{t}^{a c}, Q_{t}^{a c}$ specified real and reactive power at converter buses. real and reactive power transmitted by the $\mathrm{AC}$ network.

The AC-DC load flow problem may therefore be given in the following form using Newton Raphson method using proposed method,

$$
\left[\begin{array}{c}
\Delta \mathrm{P} \\
\Delta \mathrm{Q}
\end{array}\right]=\left[\begin{array}{ll}
\mathrm{H} & \mathrm{N}^{\prime} \\
\mathrm{J} & \mathrm{L}^{\prime}
\end{array}\right]\left[\begin{array}{l}
\Delta \dot{\theta} \\
\Delta \mathrm{V} / \mathrm{V}
\end{array}\right]
$$

Where

$$
\begin{aligned}
& N^{\prime}(t R, t R)=V_{t r} \frac{\partial P_{t R}^{a c}}{\partial V_{t R}}+V_{t R} \frac{\partial P_{d R}\left(V R \cdot V_{t R}\right)}{\partial V_{t R}} \\
& N^{\prime}(t R, t 1)=V_{t 1} \frac{\partial P_{1 R}^{a c}}{\partial V_{t 1}}+V_{t 1} \frac{\partial P_{d R}\left(V_{t R} \cdot V_{t 1}\right)}{\partial V_{t 1}} \\
& N^{\prime}(\mathrm{tI}, \mathrm{tR})=\mathrm{V}_{\mathrm{tR}} \frac{\partial \mathrm{P}_{\mathrm{tI}}^{\mathrm{ac}}}{\partial \mathrm{V}_{\mathrm{TR}}}-\mathrm{V}_{\mathrm{tR}} \frac{\partial \mathrm{P}_{\mathrm{dI}}\left(\mathrm{V}_{\mathrm{IR}} \cdot \mathrm{V}_{\mathrm{II}}\right)}{\partial \mathrm{V}_{\mathrm{tR}}} \\
& N^{\prime}(\mathrm{tl}, \mathrm{tl})=\mathrm{V}_{\mathrm{tl}} \frac{\partial \mathrm{P}_{\mathrm{Ii}}^{\mathrm{ac}}}{\partial \mathrm{V}_{\mathrm{it}}}-\mathrm{V}_{\mathrm{t}} \frac{\partial \mathrm{P}_{\mathrm{d} 1}\left(\mathrm{~V}_{\mathrm{tl}}, \mathrm{V}_{\mathrm{tl}}\right)}{\partial \mathrm{V}_{\mathrm{tl}}}
\end{aligned}
$$

The sub-matrix $L^{\prime}$ can be obtained in analogous method similar to $N^{\prime}$. Thus in the proposed solution method, four mismatch equations and up to eight elements of the Jacobian have to be modified, but no new variables are added to the solution vector, when a DC link is included in the power flow. The partial derivatives are those required by Equ (18); $\partial \mathrm{P}_{d r}\left(\mathrm{~V}_{t r}, \mathrm{~V}_{t i}\right) / \partial \mathrm{V}_{t r}$, for example, is the derivatives of $P_{d r}$ w.r.t. $V_{t r}$, assuming $V_{t i}$ is kept constant. The DC variables, however, are not kept constant as opposed to $\partial \mathrm{P}_{\mathrm{dr}}\left(\mathrm{V}_{\mathrm{tr}}, \mathrm{V}_{\mathrm{ti}}, \overline{\mathrm{X}}\right) / \partial \mathrm{V}_{\mathrm{tr}}$, which is used in Equ (18).

The presented method overcomes the major drawbacks of the other methods as it treats the real and reactive powers consumed by the converters as the 
voltage dependent loads. The DC equations are solved analytically, and the DC variables are eliminated from the power flow equations.

\section{NON-SYNCHRONOUS INTERCONNECTION}

In order to solve the power flow through non-synchronous networks connected by HVDC transmission, two AC systems have to be.handled simultaneously, i.e. two slack bases and two angle reference are needed. If the DC link connects two large networks, the inclusion of the DC link in power flow increases the number of variables. On the other hand, if the DC link feeds power from a large network to a weak island network, convergence problem for the island network can slow down in the convergence of the whole system. Thus a procedure to decouple the AC networks in power flow is desirable. The networks are coupled via the voltage magnitudes at the converter terminal $\mathrm{AC}$ buses, as shown in Equ (19):

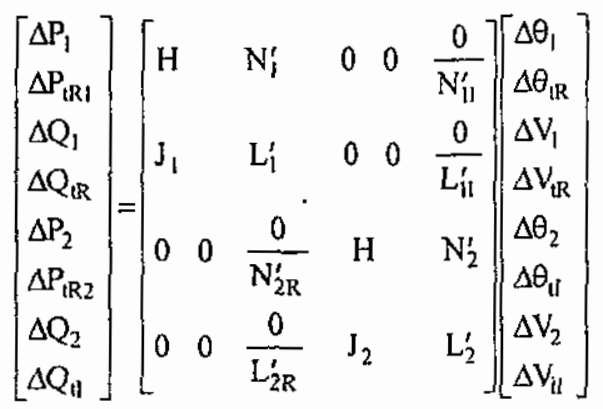

where

$\mathrm{N}_{11}^{\prime}=-\frac{\partial \Delta \mathrm{P}_{\mathrm{tR}}}{\partial \mathrm{V}_{\mathrm{tl}}}=\frac{\partial \Delta \mathrm{P}_{\mathrm{dR}}}{\partial \mathrm{V}_{\mathrm{ll}}}$

Table (1) Short Circuit Capacity of IEEE 14-Bus Test System

\begin{tabular}{|l|l|l|l|l|l|l|l|l|}
\hline Bus No. & 1 & 2 & 3 & 4 & 5 & 6 & 7 & 8 \\
\hline SCL(MVA) & 1266 & 1724 & 806 & 1254 & 1205 & 1078 & 749 & 366 \\
\hline Bus No. & 9 & 10 & 11 & 12 & 13 & 14 & & \\
\hline SCL(MVA) & 763 & 584 & 538 & 635 & 809 & 409 & & \\
\hline
\end{tabular}

Table (2) Short Circuit Capacity of IEEE 5-Bus Test System

\begin{tabular}{|l|l|l|l|l|l|}
\hline Bus No. & 1 & 2 & 3 & 4 & 5 \\
\hline SCL(MVA) & 1286 & 1810 & 1540 & 1513 & 879 \\
\hline
\end{tabular}

The only coupling between the systems are through the cross derivatives. If both the real and reactive power at the inverter end independent of the $\mathrm{AC}$ 
voltage at the rectifier end, $\mathrm{N}_{2 \mathrm{R}}$ and $\mathrm{L}_{2 \mathrm{R}}^{\prime}$ will both be zero and the power flow for the $\mathrm{AC}$ system on the inverter side can be solved independently of the $\mathrm{AC}$ system on the rectifier side. Also, once the $\mathrm{AC}$ voltage on the inverter side is known, the power flow on the rectifier side can be solved using the known value of $\mathrm{V}_{\mathrm{tI}}$.

\section{TEST RESULTS AND DISCUSSIONS}

To decide the location of DC link, the following conditions must be taken into considerations:

- The geometrical topology of the land in DC link path,

- The short circuit capacity of AC connected bus, and

- location of $\mathrm{AC}$ bus from the generating stations.

The converter requires a high reactive power consumption in commutation process. So, the converter bus must be a very strong bus with high short circuit capacity.

The IEEE 14-bus test system is connected with IEEE 5-bus test system to examine the interconnection between the two networks using an HVDC link From results the rectifier must be connected with 5-bus test system and the inverter station must be connected with 14-bus test system. This is because the 5-bus test system is more strong as compared with the 14-bus test system as illustrated from short circuit capacity of all buses of the two systems. Tables (1) \& (2) illustrate the short circuit capacity of 14-bus system and 5-bus system respectively. The voltage profile of the two test systems with different locations of DC link are illustrated in Figure (1) \& (2) for 14-bus system and 5-bus system respectively.

Tables (3) \& (4) illustrate the active and reactive power losses ( as a percentage of total active power demand ) for different positions of interconnection between the two systems.

It is found that, the best location for DC link when rectifier connected with bus 2 (5-bus system) and inverter with bus 4 (14-bus system). This choice fulfills the technical conditions mentioned previously.

Table (3) percentage active power losses for different positions of DC link between the two systems

\begin{tabular}{|l|l|l|}
\hline connected busses & percent active \\
\hline 5 -bus system & 14 -bus system & power losses \\
\hline 2 & 4 & 6.63 \\
\hline 2 & 9 & 6.71 \\
\hline 2 & 14 & 6.91 \\
\hline 3 & 4 & 7.28 \\
\hline 3 & 9 & 7.37 \\
\hline 3 & 14 & 7.57 \\
\hline 5 & 4 & 7.82 \\
\hline 5 & 9 & 7.83 \\
\hline 5 & 14 & 8.03 \\
\hline
\end{tabular}


Table (4) percentage reactive power losses for different positions of DC link between the two systems

\begin{tabular}{|l|l|l|}
\hline connected busses & percent reactive \\
\hline 5 -bus system & 14 -bus system & power losses \\
\hline 2 & 4 & 34.49 \\
\hline 2 & 9 & 35.15 \\
\hline 2 & 14 & 35.27 \\
\hline 3 & 4 & 37.49 \\
\hline 3 & 9 & 36.82 \\
\hline 3 & 14 & 37.60 \\
\hline 5 & 4 & 38.36 \\
\hline 5 & 9 & 38.37 \\
\hline 5 & 14 & 39.15 \\
\hline
\end{tabular}

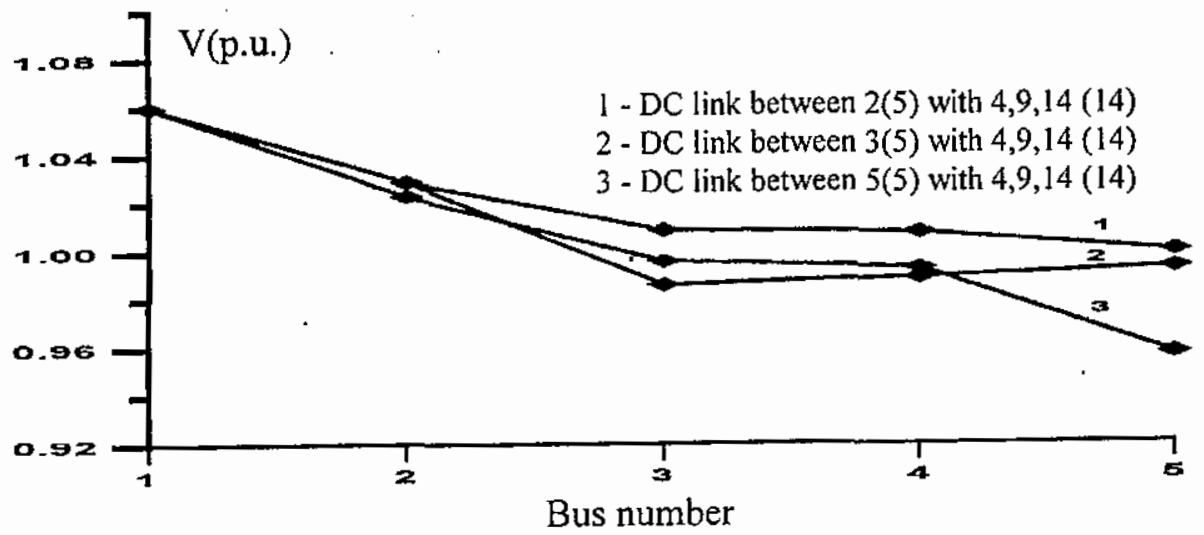

Figure (3) voltage profile of 5-bus system for different positions of . connection between the two systems

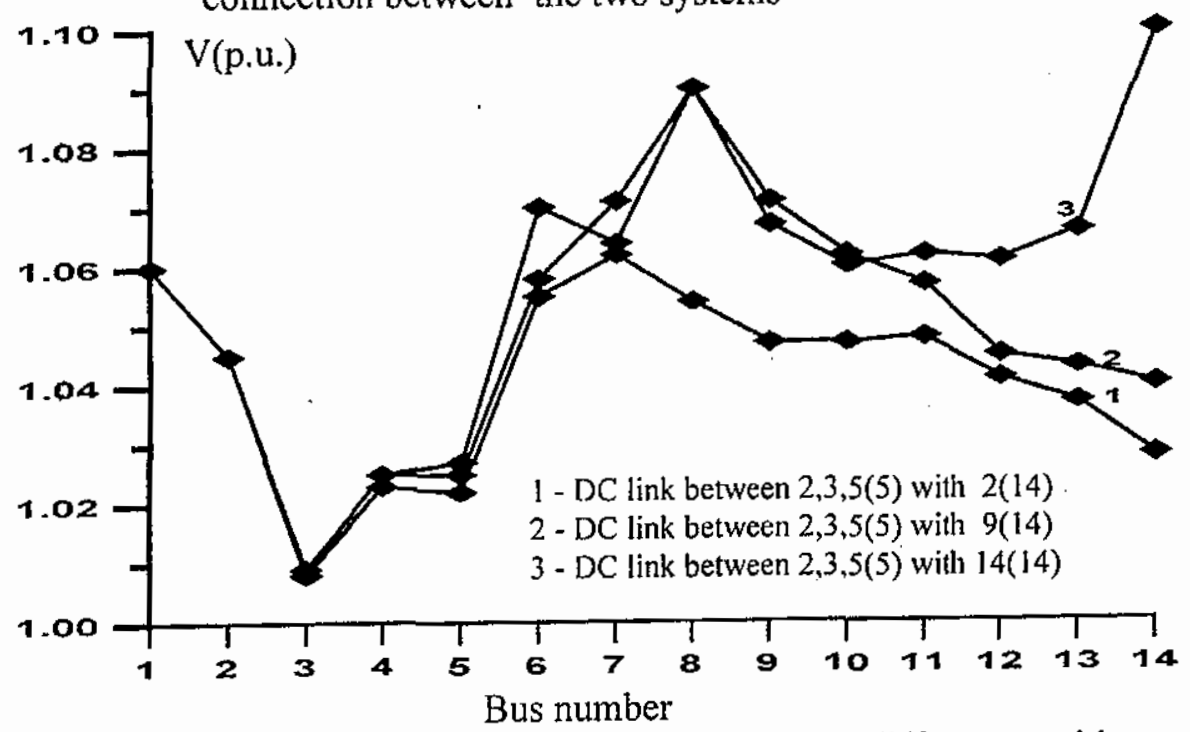

Figure (4) voltage profile of 14-bus system for different positions of connection between the two systcms 


\section{CONCLUSION}

The non-synchronous interconnection between two $\mathrm{AC}$ systems has a difficulty of two slack buses and two references for power flow problem. The proposed method is modified to handle the concept of networks interconnection, which allows the power flow for two $\mathrm{AC}$ networks in non synchronous interconnection to be solved independently. The modified method is successfully utilized to interconnect between IEEE 5-bus test system and IEEE 14-bus test system to determine the best location of the DC link taking into account all technical considerations.

\section{REFERENCES}

[1] H. Fudeh, C.M. Ong, "A Simple and Efficient AC-DC Load-Flow Method for Multiterminal DC Systems", IEEE transactions on Power Apparatus and Systems, Vol.PAS-100, No.7, pp. 4389-4396, 1981.

[2] J. Arrillaga, C. P. Arnold, B. J. Harker, 'Computer Modelling of Electrical Power Systems', John Wiley and Sons, 1983.

[3] R. Lee, M. J. Beshir, J. H. Gee, "Planning Considerations for the Intermountain HVDC Transmission System", IEEE transactions on Power Delivery, Vol. PWRD-1, No.1, pp.225-231, January 1986.

[4] T. Smed, G. Anderson, G. B.Sheble, L.Grigsby, "A New approach to AC/DC Power Flow", IEEE Trans, on Power Systems, Vol.6, No.3, pp.1238-1244, August 1991.

[5] K. M Shebl, M. E. El-Said, H. El-Desouki, I. Bedir, "An Efficient Method for HVDC Transmission System Analysis", Six Middle East Power System Conference (MEPCON 98), Mansoura, Egypt, pp. 259266, December 1998.

[6] Ravindra S. Kuruneru, Anjan Bose, Richard Bunch, "Modeling of High Voltage Direct Current Transmission Systems for Operator Training Simulators", IEEE transaction on Power Systems, Vol. 9, No. 2, pp. 714-720, May 1994.

[7] I. Bedir, "Analysis of High Voltage Direct Current Transmission", M.Sc. Thesis, Faculty of Engineering, El-Mansoura University, 1999. 


\section{الطريقة المعدلة لدراسة سريان القدرة بين الثبكات المرتبطة ترابط غير متز امن}

يقدم هذا البحث طريقة هثالية لعملية سريان القدرة الكهربية تستخدم لدراسة ســيان القدرة للشبكات المرتبطة (ذات تردد مختلف ) من خلال خط ربط غير مســتز امن وتعالج هذه الطريقة المعدل على أنه حمل بعتمد على الجهد مع حسـذف متخـيرات النظلام المستمر من معادلات سريان القدرة الكهربية ، وقد تم تطبيق هذه الطريقــة للربط بين نظامين من النوع القياسى حيث ينكون الأول من خمس نقــاط ثوزيـــع بينما يتكون الأخر من أربعسـة عشسر نقطــة (IEEE 5-Bus Test System ) توزيع ( IEEE 14-Bus Test System ) مع أخذ الشروط الفنية لعملية الربــط فى الاعتبار و هذه الشُروط هى قرب نقطة الربط من مناطق التوليـــــ ، أن يكـون مسار الربط مناسب جغرافيًاً، وأن يكون مسنوى القصر النقطة الربط عالى. 